\title{
Videotaped OSPE: Is This a Right Procedure to Assess Health Science Students' Performance? - A Pilot Study
}

\author{
R. Vinodh Kumar
}

\begin{abstract}
The performance based student assessment during OSPE, challenge the examiners accurately capturing students' practical skills. In order to solve this problem, this study introduces a new Innovative procedure of videotaped objective structured practical examination (VOSPE) in the area of health care education to support the existing objective structured practical exam (OSPE). The purpose of this study is to introduce the videotaped OSPE among fifth semester physiotherapy students to assess their stress level and performance irregular objective structured practical exam (ROSPE). Statistical analysis by one way ANOVA reported that there is no significant difference $(P=0.578$ and $P=0.095)$ in the students' performance between the three stations. The student's survey feedback favors VOSPE for practical exam, which could be new method in the health science curriculum, support to increase OSPE station numbers, compensate personnel and to reduce examiner fatigue.
\end{abstract}

Index Terms-OSPE, physiotherapy, ROSPE, VOSPE, videotaped.

\section{INTRODUCTION}

Knowledge and practical skills play an important role in the health science profession, which has to be ensured with quality assessment to assure better performance of students. "Strong base is the pillar for good foundation," Objective structured practical exam (OSPE) prepares outlook among students to face objective structured clinical exam (OSCE) in clinical setting [1]-[3]. During OSPE, the individual students' competency level in physiotherapy skills [4] tested more objectively with predetermined set of techniques and questions [5]. Assessment of one's own ability is challenging and often inaccurate [6] and peer feedback provides accuracy in assessment [7]. Determining a valid and reliable outcome in practical exam was a challenging task in an institution with less stations and personnel [8]. The live Video recording in the practical exam station covers the existing issues on OSPE marking. Videotaped objective structured practical examination (VOSPE) will address the repeated suggestions regarding the examiner fatigue and intimidate in regular objective structured practical exam (ROSPE), which increases the pressure level for both staff and students.

Evidence plays a major role in health care education and practice. Technology contributes to the evidence based assessment procedure in practical exam to face the challenges and move towards a change. Incorporating the feasible technology in health science will strongly strengthen the

Manuscript received July 10, 2014; revised October 21, 2014.

R. Vinodh Kumar is with the INTI International University, Faculty of Health Science, Nilai, Malaysia (e-mail vinodh.ramalingam@newinti.edu.my). students' performance and evaluating procedures. Video shooting and learning in the modern education ease the student's attention and interactions. Videotaped station can be a standard practical assessment procedure in marking, even with off campus examiners, and is also useful to retrieve the evidence of students' performance in future [9]. Experts had mentioned in early studies to modify the OSPE procedures based on local circumstances in educational institutes [8].

"The staff and students perception about OSPE highlights the need to improve in the way which OPSE evaluation maintains the objectivity" [10]. From the reviewed studies, only OSCE's used new practical methods and progressed using video recording, computer assisted procedures and video projectors. Although studies shown that OSPE was a reliable method, the current OSPE procedures carried with single or two OSPE stations is not enough to test the learning outcome of the student [11]. So an idea emerged to introduce videotape OSPE in the ROSPE, to evaluate the students' performance. Based on that idea this study had been initiated with three questions.

1) Is VOSPE a right procedure to assess student performance?

2) Is presence of examiner in OSPE station will increase student stress level?

3) Will the student perform better in the videotape OSPE station?

In order to answer the above-mentioned research questions, the following objectives are set forth for the study:

1) To evaluate the effectiveness of students' performance in VOSPE.

2) To obtain the student feedback on stress level, and performance in VOSPE

3) To evaluate the students' performance in VOSPE station and compare with regular OSPE stations.

\section{METHODS}

\section{A. Data Collection}

The pilot trial was carried out with all the 28 students who attended their regular coursework OSPE in Musculoskeletal physiotherapy at INTI International University by convenience sampling method. The participated students in this trial were well exposed to OSPE practical procedures from second year. The third year students from fifth semester were selected in this study to avoid the bias of unfamiliarity with ROSPE stations. Before starting this study, the new method was discussed in the classroom with the students and as all the students expressed positive opinion about the procedure this study was planned in the coursework OSPE. 
Signed informed consent was taken from each student with a guarantee that the video will be used only to evaluate the performance for the given procedure.

\section{B. OSPE Structure}

OSPE is an essential exam for major subjects in physiotherapy degree program at INTI International University to evaluate students' practical knowledge and hand on skills. The Practical exam weighs $30 \%$ of the total marks for the musculoskeletal physiotherapy course and is measured through two modules (coursework OSPE-I and OSPE-II). This trail was carried out in module OSPE-II to test the student's communication, interaction, explanation, demonstration of practical skills and performance of special tests. The VOSPE and ROSPE marking check list was prepared by the concerned lecturer and validated (face and content validation)by the subject specialists in the Faculty of Health Sciences. In line with the scheduled date the OSPE exam was conducted with three stations; station one was videotaped for the given procedure. It was set-up with the tripod supported digital video camera to videotape (record) the individual student's performance. One student model was present in each station and advised to follow the instructions provided by the students and not to perform anything other than that. The question was displayed on the right side wall of the performer for convenience. The assigned quarantine staff monitors the entire OSPE cycle initiating with briefing; the time keeper maintains five minutes for each station. After five minutes, he rings electronic bell and allows one minute space time for exchange between stations. The student undergoing exam in station one was instructed to start the video camera, position them on the marked standing point and proceed to the given procedure. In station one student were specially instructed to perform facing the camera. The students' performance in ROSPE stations two and three were scored by assigned examiner based on the given checklist. The videotape data storage was transferred to computer and marked by the concerned subject lecturer based on the scoring checklist.

\section{Student Feedback}

The 9-item, self-constructed questionnaire with five point liker scale (strongly agree, agree, neutral, disagree and strongly disagree) was prepared and directed to face and content validation before publishing in Google docs "Table I," For easy accessibility, Google docs "Table I" URL link was posted in face book (third year fifth semester group) and requested to respond all the items in the questionnaire. The link was kept in open access for three days prior to the release of coursework result. Only 25 students responded in the given time, the link had been closed on the third day and their feedbacks were analyzed.

\section{Data Analysis}

The data were analyzed using one way ANOVA using IBM SPSS version 20 to find the significance between videotaped and regular OSPE stations (ROSPE1 and ROSPE2). The mean, median, standard deviation, variance was done by descriptive analysis to differentiate the student performance in each station "Table II," The liker scale with five options from 1 (strongly disagree) to 5 (strongly agree) was used in 9-items questionnaire to analyze the student's feedback and responses "Table I,"

\section{RESULT}

The mean values of VOSPE station were slightly lower $(17.96 \pm 2.15)$ when compared with the other two ROSPE $(18.39 \pm 1.93$ and $18.35 \pm 1.88)$ stations. The variance between student score in videotaped OSPE was higher 4.628 compared with ROPSE 3.729 and 3.571 shows consistence in mark distribution "Table II," The students' performance in VOSPE distribution "Fig. 1" shows good and average performers differences comparing with ROSPE "Fig. 2," and "Fig. 3," The One way variance ANOVA analysis shows the ROSPE1 $F(7,27)=0.826, p=0.578$ and ROSPE2 $F(7,27)$ $=2.075, p=0.095$, shows that there is no significant difference between the students' performance between VOSPE and ROSPE stations "Table III," The 25 respondents' feedback shows that $73 \%$ of students agree to the information in the VOSPE station $64 \%$ of students agree that stress freer in absence of examiner; only $48 \%$ of students agree that videotaped station support their performance.

\begin{tabular}{|c|c|}
\hline \multicolumn{2}{|c|}{ Items } \\
\hline \multicolumn{2}{|r|}{ Information } \\
\hline 1 & $\begin{array}{c}\text { Have you been informed well about the video OSPE } \\
\text { procedure? }\end{array}$ \\
\hline 2 & Was your video OSPE station well organized? \\
\hline 3 & $\begin{array}{l}\text { Was the question displayed in the station clear and } \\
\text { understandable? }\end{array}$ \\
\hline 4 & $\begin{array}{l}\text { Did you miss any required information in the absence of } \\
\text { examiner? }\end{array}$ \\
\hline \multicolumn{2}{|r|}{ Stress level } \\
\hline 5 & $\begin{array}{l}\text { Did you feel the video station is stress freer than regular OSPE } \\
\text { stations? }\end{array}$ \\
\hline 6 & $\begin{array}{l}\text { Did the video station help you in recollecting the required } \\
\text { information in the absence of examiner? }\end{array}$ \\
\hline 7 & Did you feel more confident in the absence of examiner? \\
\hline \multicolumn{2}{|c|}{ Performance } \\
\hline 8 & $\begin{array}{l}\text { Do you believe this method will increase your OSPE } \\
\text { performance score? }\end{array}$ \\
\hline 9 & $\begin{array}{l}\text { Do you recommend the video based OSPE for upcoming } \\
\text { semesters? }\end{array}$ \\
\hline
\end{tabular}

TABLEII: DESCRIPTIVE ANALYSIS OF VOSPE AND ROSPE

\begin{tabular}{|l|c|c|c|}
\hline & VOSPE & ROSPE1 & ROSPE2 \\
\hline N Valid & 28 & 28 & 28 \\
Missing & 0 & 0 & 0 \\
\hline Mean & 17.9643 & 18.3929 & 18.3571 \\
Median & 18.0000 & 19.5000 & 19.5000 \\
Std. Deviation & 2.15135 & 1.93102 & 1.88982 \\
Variance & 4.628 & 3.729 & 3.571 \\
\hline
\end{tabular}

$5 \%$ of students reports that they missed information in the absence of examiner in VOSPE station, 22\% of students were neutral, $13.33 \%$ felt stressful and 22.67 neutral. Only $12 \%$ of students disagree that their OSPE performance would not increase by VOSPE and remaining $40 \%$ of students were neutral. 
TABLE III: ONE WAY ANOVA ANALYSIS REPORT

\begin{tabular}{|c|c|c|c|c|}
\hline & Sum of & dif & Mean & $F$ \\
\hline ROSPE1 & squares & square & \\
Between groups & 22.571 & 7 & 3.224 & \\
With groups & 78.107 & 20 & 3.905 & \\
Total & 100.679 & 27 & & \\
\hline ROSPE2 & & & & \\
Between groups & 40.564 & 7 & & \\
With groups & 55.864 & 20 & 5.795 & \\
Total & 96.429 & 27 & & \\
\hline
\end{tabular}

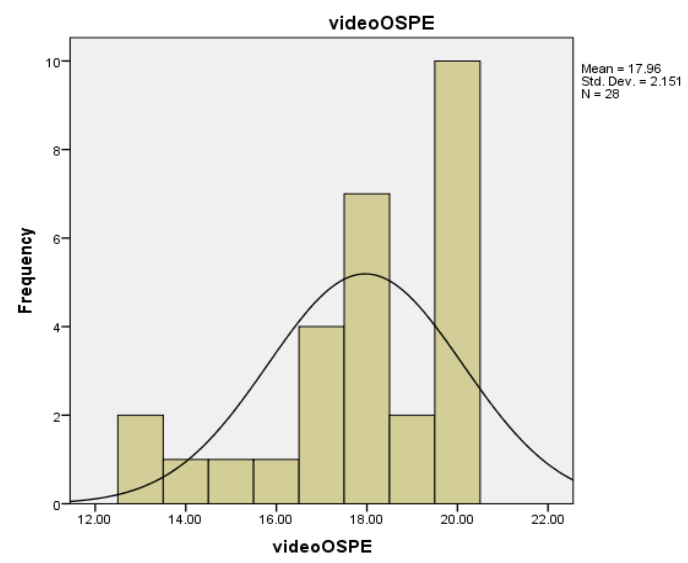

Fig. 1. Students score distribution VOSPE.

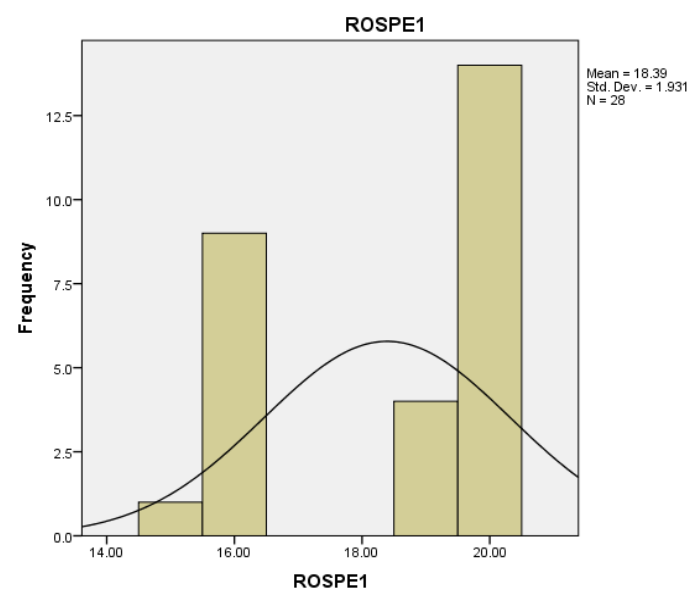

Fig. 2. Students score distribution ROSPE1.

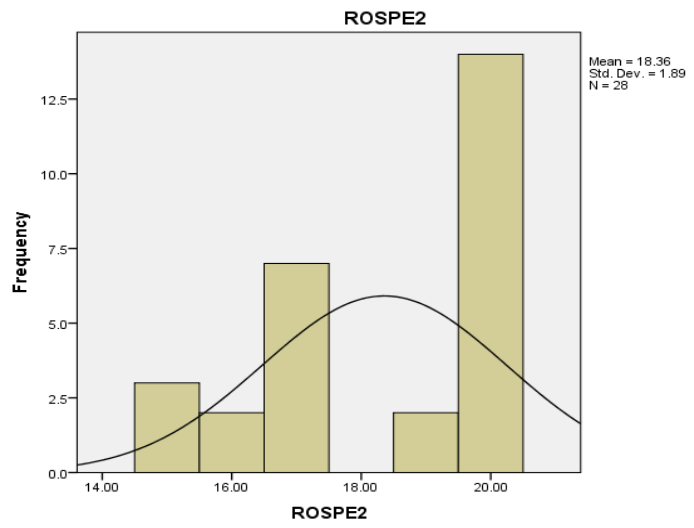

Fig. 3. Students score distribution ROSPE2.

\section{DISCUSSION}

Assessing the practical exam is challenged to enhance competency among individual student in the health care profession. OSPE is a right approach to examine the students' performance components to incorporate sound platform for physiotherapy students to enter the clinical practice. The well designed and implemented VOSPE added with the regular OSPE as a method of assessing students' performance demonstrates the quality practical assessment. When comparing the overall mean scores the students' performance in the three stations had no significant difference, but the variance between the performers in VOSPE station was higher compared with ROSPE. Similar variance was reviewed from [12] the video recorded OSCE performance of students (Cranach's alpha 0.621 and the mean inter-item correlation 0.15 ) and the video station discriminated well between good and poor candidates.

The variance among students performance was 4.628in VOSPE since it was marked in the leisure time after the practical exam, which overcomes the existing issues of examiner fatigue leading would be ignored and missed student performance as reported in OSCE the previous study [13]. This most commonly happens in the practical and clinical examinations, the marker don't have a chance to track the performance, which can get solved in the VOSPE. The issue of reliable method OSPE procedures [2] carried with single or two OSPE stations is not enough to test the learning outcome of the student was also addressed. Available advances in computer and software technology offer several advantages for the administration and computerized examination in medical education [14]. Even though there is no preference for VOSPE based on one way ANOVA, this method could help in increasing the number of OSPE stations and test the student's competence, by minimizing inter-examiner variability, limiting cost and organizational burdens [15].

Stress or exam fear was one of the common fact student faces in exam sessions. This will differ among students. The limiting factor reported in the "study on standardized and quality assured video recorded examination in undergraduate education", that they have not investigated students feedback on video recording has been addressed in this trial [16]. Students' feedback is considered a key indicator for successful implementation of VOSPE. Based on the students' feedback response 64\%was stress freer in absence of examiner when comparing with $63.2 \%$ felt stressed in the presence of examiner in OSPE [11]. In absence of examiner the $73 \%$ of student agree that the information was very clear and does not miss the examiner during the performance, but only $5 \%$ of student who miss the examiner, focused towards expecting clues to get the answer in practical performance while the remaining $22 \%$ of student was neutral. Even though the feedback on information of stress level among the respondent were supportive, $48 \%$ of student agree, $40 \%$ of student are neutral and $12 \%$ of student disagree that VOSPE improves the performance. $56 \%$ of student recommended for the forthcoming semesters, $32 \%$ neutral and $12 \%$ disagree. So the feedback response highlights that the students are well aware that videotaping marking would scrutiny their 
performance and affects their score. So the recommendations of VOSPE in the upcoming semester were very few.

\section{LIMITATION}

The accuracy of student's performance in the VOSPE station have to be inter rated with internal and external marker for reliability, and the feedback regarding time availability in VOSPE have to be highlighted to reduce the stress level during performance.

\section{CONCLUSION}

This pilot trial shows VOSPE is a feasible method which can be implemented in the health sciences curriculum. This procedure enhances accuracy in marking, can be used as digital study material with concern and also evidence of student performance in review process. Reduction in stress level recommends the VOSPE as the future student performance measuring tool.

\section{ACKNOWLEDGMENTS}

I would like to thank my Dean Faculty of Health Science Prof. Dato' Dr. Ibrahim Ahmad Bajunid, Head of program Mr. Jayaprabha Surendran Praveen, colleagues for motivation and support to carry this trail, and third year physiotherapy students for their participation. Special thanks to $\mathrm{Mr}$. Thirumalaya Balaraman and Mr. Muthukaruppan for their valuable comments and suggestions.

\section{REFERENCES}

[1] R. M. Harden, G. M. Wilson et al., "Assessment of clinical competence using objective structured examination,” British Medical Journal, vol. 1, pp. 447-451, 1975.

[2] M. Nayar, "An overview of the objective structured clinical examination," Physiotherapy Canada, vol. 45, no. 3, pp. 171-178, 1993.

[3] M. Nicol and D. Freeth, "Assessment of clinical skills: A new approach to an old problem," Nurse Education Today, vol. 18, pp. 601-609, 1998.

[4] World Confederation for Physical Therapy, WCPT Guideline for Physical Therapist Professional Entry Level Education, London: WC PT Secretariat, 2011, pp. 1-42.

[5] M. L. Mitchell, A. Henderson, M. Groves, M. Dalton, and D. Nulty, "The objective structured clinical examination (OSC E): Optimising its value in the undergraduate nursing curriculum," Nurse Educ. Today, vol. 29, no. 4, pp. 398-404, 2009.

[6] D. A. Davis, P. E. Mazmanian, M. Fordis, V. R. Harrison, K. E. Thorpe, and L. Perrier, "Accuracy of physician self -assessment compared with observed measures of competence," A Systematic Review, vol. 296, pp. 1094-1102, 2006.

[7] K. W. Eva and G. Regehr, "Self-assessment in the health professions: A reformulation and research agenda," Acad Med., vol. 80, pp. 46-54, 2005.

[8] N. Ananthakrishnan, "Objective structured clinical/practical examination (OSCE/OSPE)," J. Postgrad Med., vol. 39, p. 82, 1993.

[9] P. Vivekananda-Schmidt, M. Lewis, D. Coady et al., "Exploring the use of videotaped objective structured clinical examination in the assessment of joint examination skills of medical students," Arthritis Rheum, vol. 57, p. 869, 2007.

[10] J. M. Frantz et al., "Student and staff perceptions and experiences of the introduction of objective structured practical examinations: A pilot study," AJHPE, vol. 5, no. 2, pp. 72-74, 2013.

[11] N. Al-Mously, "Student feedback on OSPE: An experience of a new medical school in Saudi Arabia," IAMSE, pp. 10-16.

[12] E. A. Webb et al., "Improving postgraduate clinical assessment tools: The introduction of video recordings to assess decision making," Medical Teacher, vol. 34, pp. 404-410, 2012.

[13] G. J. Gormley et al., "Awarding global grades in OSCEs: Evaluation of a novel eLearning resource for OSCE examiners," Medical Teacher, vol. 34, pp. 587-589, 2012.

[14] R. W. Ogilvie, T. C. Trusk, and A. V. Blue, "Students' attitudes towards computer testing in a basic science course," Med. Educ., vol. 33, pp. 828-831, 1999.

[15] K. Walters, D. Osborn, and P. Raven, "The development, validity and reliability of a multimodality objective structured clinical examination in psychiatry," Med. Edu., vol. 39, no. 3, pp. 292-298, 2005.

[16] C. Kiehl et al., "Standardized and quality-assured video-recorded examination in undergraduate education: informed consent prior to surgery," Journal of Surgical Research, 2014, pp. 1-10.

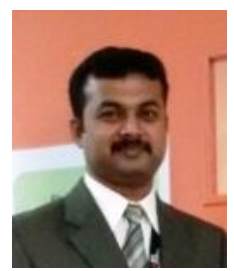

Vinodh Kumar Ramalingam was born in Namakkal, India, on October 10, 1979. He was graduated with the bachelor in physiotherapy (2001) and masters in sports physiotherapy (2003) from Annamalai University, Chidambaram, Tamilnadu. India. He is focused on musculoskeletal and sports physiotherapy. He has over 11 year experiences in the field of physiotherapy. Currently he is positioned as a senior lecturer in INTI International University, Malaysia, and also worked in various institutions (national and international) and handle challenging positions. The challenging part and good time in his experience was as the head of physiotherapy (2008) in AWH special college, Kerala (India). He had sound clinical judgment in assessing, diagnosing, and planning, treating, documenting and evaluating process of Physiotherapy. As a person of multidisciplinary approach, he was always ready to work in team and also with other health care professionals. He had published abstract in Malaysian Journal of Public Health Medicine on Topic "Balance training for athlete's with repetitive ankle sprain". His interests include innovation towards new ideas relate with physiotherapy. 